\title{
Movimentos sociais e coletivos no Brasil contemporâneo: horizontalidade, redes sociais e novas formas de representação política
}

\author{
Social movements and collective in contemporary Brazil: \\ horizontality, social networks and new forms of \\ political representation
}

Movimientos sociales y colectivos en el Brasil contemporáneo: horizontalidad, redes sociales y nuevas formas de representación política

Recebido em 31-08-2020

Modificado em 07-10-2020

Aceito para publica em 21-10-2020

\section{Mariana Zanata Thibes}

ORCID: 0000-0002-6050-1160

Doutora em Sociologia pela USP e pós-doutorado em Ciências Sociais pela UFABC e PUC/SP, sob os auspícios da FAPESP. Pesquisadora do NEAMP (Núcleo de Estudos em Arte, Mídia e Política da PUC/SP) e membro do Privacy Research Group (NYU). E-mail: mthibesster@gmail.com

\section{Natasha Bachini Pereira}

ORCID: 0000-0001-6737-6190

Doutoranda no Programa de Pós-graduação em Sociologia do Instituto de Estudos Sociais e Políticos da Universidade do Estado do Rio de Janeiro (IESP-UERJ). Pesquisadora do Núcleo de Estudos de Teoria Social e América Latina (NETSAL) e do NEAMP (PUC/SP). Docente da Fundação Escola de Sociologia e Política de São Paulo (FESPSP). E-mail: natashabachini@iesp.uerj.br

\section{Rosemary Segurado}

ORCID: 0000-0002-3910-4603

Doutora em Ciências Sociais pela PUC/SP, pós-doutora em Comunicação e Política pela Universidade Rey Juan Carlos de Madrid. Docente do Programa de Estudos Pós-graduados em Ciências Sociais pela PUCSP e da Escola de Sociologia e Política de São Paulo. Pesquisadora do NEAMP (Núcleo de Estudos em Arte, Mídia e Política da PUC/SP). E-mail: roseseg@uol.com.br

\section{Tathiana Senne Chicarino}

ORCID: 0000-0002-9306-5668

Doutora em Ciências Sociais pela Pontifícia Universidade Católica de São Paulo (PUC/SP). Docente da Fundação Escola de Sociologia e Política de São Paulo. Pesquisadora do NEAMP (PUC/SP) e do Grupo de Pesquisa Comunicação e Sociedade do Espetáculo da Casper Líbero. E-mail: tschicarino@gmail.com 


\section{Resumo}

$\mathrm{O}$ artigo apresenta os resultados parciais de uma pesquisa empírica feita com atores coletivos de diversas regiões do Brasil, a partir da análise de entrevistas realizadas nos estados de São Paulo, Bahia, Maranhão, Rio Grande do Sul, Ceará e Mato Grosso do Sul. Foram abordadas questões sobre a estrutura, a organização, a concepção da ação política e coletiva, o papel das lideranças e as formas de comunicação das organizações. Com o objetivo de observar os variados modos contemporâneos de ativismo político e cultural no país, destacamos os sujeitos que emergiram na disputa política recente com foco na crítica à representação, atentando especialmente para um tipo que ainda foi pouco estudado pela literatura: os coletivos.

Palavras-chave: movimentos sociais; coletivos; ativismo político; ativismo cultural; horizontalidade; representação política.

\section{Introdução}

Neste artigo apresentamos os resultados parciais de uma pesquisa empírica feita com coletivos e movimentos de diversas regiões do Brasil, entre 2013 e 2019. Financiado pela FAPESP $^{1}$, o projeto abordava o exercício da liderança política no país, do Império aos dias atuais, em suas diferentes manifestações. A pesquisa foi estruturada em dois eixos: lideranças e organizações. No âmbito das organizações, foram inclusos os partidos políticos e os atores coletivos, entendidos como aqueles que protagonizam ação que é realizada, coletivamente, com vistas a alcançar objetivos de um grupo específico. Além de um banco de dados ${ }^{2}$ com informações biográficas sobre lideranças, partidos e atores coletivos, foi feita uma pesquisa empírica com entrevistas qualitativas às primeiras e aos últimos. Nesse artigo, trataremos especificamente da parte do projeto relativa aos atores coletivos, embora a temática dos partidos e das lideranças perpasse a todo o momento a argumentação.

Os partidos políticos são historicamente as principais organizações de representação política da sociedade moderna e já passaram por diversas configurações, a depender do contexto socio-histórico em que estiveram presentes. Da segunda metade do século XX em diante, destacaram-se desde os partidos de massa, típicos da sociedade fordista (Mair, 2013), com estruturas altamente burocratizadas, hierarquizadas e centralizadas, orientação ideológica

1 O Projeto Temático (n 12/50987-3) "Lideranças Políticas no Brasil: características e questões institucionais" foi financiado pela FAPESP. As opiniões, hipóteses e conclusões ou recomendações expressas neste trabalho são de responsabilidade dos autores e não necessariamente refletem a visão da FAPESP.

$2 \mathrm{O}$ banco de dados, com as fichas de lideranças políticas, partidos e atores coletivos será disponibilizado em um site a ser divulgado em breve. 
e base de classe bem definidas, até as formas mais dinâmicas e flexíveis. Estas últimas foram ganhando lugar a partir do desenvolvimento dos meios de comunicação, da crise de acumulação do capitalismo fordista e da crítica dos movimentos sociais emergentes desde o final dos anos 1960, tornando-se progressivamente mais flexíveis em suas estruturas e na formação da base, caminhando rumo a configurações que utilizam amplamente a televisão e a propaganda para comunicar-se com um eleitorado cada vez mais amplo e dinâmico em seus desejos e intenções. O eleitorado, por sua vez, passou a ser abordado como parte de um "mercado eleitoral" (Gerbaudo, 2018:34), mediante técnicas de marketing bastante semelhantes àquelas usadas no mercado de bens comuns. Nesses partidos, é também central a figura de um líder, cuja popularidade depende largamente do carisma e das qualidades pessoais passíveis de serem televisionadas. Essa forma foi largamente criticada pelos movimentos sociais contemporâneos por corresponder a um eleitor passivo e apático, mais interessado pelo espetáculo televisivo do que pela política em si.

Essa crítica tornou-se ainda mais contundente na década de 2010, com a emergência da Primavera Árabe, do Occupy Wall Street e do surgimento dos partidos digitais, os quais, de diferentes maneiras, denunciaram a falta de participação e representação políticas das "velhas" entidades partidárias.

O grande marco dessa crítica no Brasil foram as Jornadas de Junho de 2013. Questão central para os atores coletivos que protagonizaram as Jornadas foi o questionamento das formas tradicionais de liderança e representação. Convocados inicialmente pelo Movimento Passe Livre (MPL), os atores individuais e coletivos confluíram na crítica às instituições políticas tradicionais, tais como partidos políticos, sindicatos e movimentos sociais tradicionais, a partir da problematização dos mecanismos da representação e do distanciamento das instituições da população de maneira geral. Traziam a demanda por espaços de atuação política horizontais e maior responsabilidade com o dinheiro público.

As manifestações e seu saldo político foram amplamente debatidos, porém, pouco se sabe sobre como os atores coletivos continuaram sua atuação depois da fase efervescente dos protestos. As mudanças da conjuntura política recente alteraram significativamente sua posição no campo político, o que impactou na realização da pesquisa, como será detalhado adiante, e colocou novos desafios à sua atuação. Nossos esforços aqui pretendem contribuir para preencher essa lacuna, analisando as características principais de atores coletivos contemporâneos, tais como a estrutura organizativa, formas de liderança e financiamento, estratégias de comunicação (sobretudo a apropriação das redes sociais) e a crítica que perfazem sobre a representação democrática atual. 
A pesquisa teve duas fases principais: a primeira consistiu no levantamento de informações sobre coletivos e movimentos sociais brasileiros e sua inserção num banco de dados; na segunda, foram feitas entrevistas ${ }^{3}$ com 40 atores coletivos dos estados de São Paulo, Bahia, Maranhão, Rio Grande do Sul, Ceará e Mato Grosso do Sul, de onde provém nosso material empírico. Os atores coletivos foram selecionados tanto com base na relevância de sua atuação na região quanto à disponibilidade em conceder a entrevista. Nesse sentido, o quadro de entrevistas não pode ser considerado representativo das regiões devido às limitações explicitadas.

\begin{tabular}{|c|c|c|c|}
\hline Ator Coletivo & Cidade & Região & Área De Atuação \\
\hline Reocupa & São Luís & NE & Cultura \\
\hline Curta Diversidade & São Luís & NE & Cultura \\
\hline NAFEM (Núcleo Artístico Feminista) & São Luís & NE & Feminismo \\
\hline Fórum Maranhense de Mulheres & São Luís & NE & Feminismo \\
\hline Levante Popular da Juventude & São Luís & $\mathrm{NE}$ & Direitos Humanos \\
\hline Catarse Coletivo De Comunicação & Porto Alegre & $\mathrm{S}$ & Cultura \\
\hline Matehackers & Porto Alegre & $\mathrm{S}$ & Cultura Hacker \\
\hline Quilombo Do Sopapo & Porto Alegre & $\mathrm{S}$ & Cultura \\
\hline Grupo 3 de Nós & Porto Alegre & $\mathrm{S}$ & Cultura \\
\hline Baixa Cultura & Porto Alegre & $\mathrm{S}$ & Cultura \\
\hline Casa de Cultura Digital & Porto Alegre & $\mathrm{S}$ & Cultura \\
\hline Nonada Jornalismo & Porto Alegre & $\mathrm{S}$ & Cultura \\
\hline Coletivo Germina & Porto Alegre & $\mathrm{S}$ & Cultura \\
\hline Acopamec & Salvador & $\mathrm{NE}$ & Educação \\
\hline Hortas Urbanas de Salvador & Salvador & NE & Meio-Ambiente \\
\hline Coletivo das Liliths & Salvador & $\mathrm{NE}$ & LGBT \\
\hline Coletivo Musas & Salvador & $\mathrm{NE}$ & LGBT \\
\hline $\begin{array}{l}\text { MSTS (Movimento dos Trabalhadores sem teto de } \\
\text { Salvador) }\end{array}$ & Salvador & $\mathrm{NE}$ & Habitação \\
\hline MSTB (Movimento dos Trabalhadores sem teto da Bahia & Salvador & $\mathrm{NE}$ & Habitação \\
\hline Coletivo da Queda & Salvador & NE & Cultura \\
\hline Coletivo Flor no Asfalto & Fortaleza & NE & LGBT \\
\hline Movimento de Mulheres Olga Benário & Fortaleza & $\mathrm{NE}$ & Feminismo \\
\hline Coletivo Baderna & Fortaleza & $\mathrm{NE}$ & Direitos Humanos \\
\hline Fórum Cearense de Mulheres & Fortaleza & NE & Feminismo \\
\hline Crítica Radical & Fortaleza & NE & Política \\
\hline Ponte Jornalismo & São Paulo & SE & Comunicação \\
\hline MTST & São Paulo & $\mathrm{SE}$ & Habitação \\
\hline Desentorpecendo a Razão (DAR) & São Paulo & SE & Antiproibicionismo \\
\hline Outras Palavras & São Paulo & SE & Comunicação \\
\hline
\end{tabular}

3 Os vídeos serão disponibilizados para consulta pública ao final do projeto. 


\begin{tabular}{|l|c|c|c} 
Vem pra Rua & São Paulo & SE & Política \\
União de Mulheres & São Paulo & SE & Feminismo \\
Marcha das Mulheres Negras & São Paulo & SE & Feminismo Negro \\
Parada LGBT & São Paulo & SE & LGBT \\
Movimento Brasil Livre & São Paulo & SE & Política \\
Movimento Passe Livre & São Paulo & SE & Transporte \\
Caminhada Lésbica & São Paulo & SE & LGBT \\
Plataforma Brasileira de Política de Drogas & São Paulo & SE & Antiproibicionismo \\
Movimento Indigenista da etnia Guarani Kayowaá & Dourados & CO & Direitos Humanos \\
Marcha Mundial de Mulheres de Dourados & Dourados & CO & Feminismo \\
Coletivo Antiproibicionista de Pernambuco (CAPE) & Recife & NE & Antiproibicionismo \\
Coletivo Joaquim Nabuco de Defesa do Liberalismo & Recife & NE & Política \\
\hline
\end{tabular}

Fonte: Dados da pesquisa.

Como se tratava de um fenômeno novo e de um campo vasto a ser percorrido, decidimos que a abordagem mais adequada seria uma espécie de grounded theory que nos permitisse um envolvimento com o fenômeno sem a modulação prévia de uma instrumentação teórica consolidada, para criar uma abertura maior ao que o campo enunciasse. Em uma fase posterior, a partir da confirmação ou refutação de nossas hipóteses, poderíamos fazer emergir uma reflexão teórica a partir dos achados. Talvez por essa razão, o leitor se depare com um trabalho que se encontra ainda, em grande medida, em construção. Apesar disso, essa escolha foi fundamental para nos preparar para diversos imprevistos que surgiram ao longo do percurso.

A realização da pesquisa de campo em âmbito nacional sem dúvida a enriquece e viabiliza uma análise ampla e comparativa em um campo propenso a análises de casos isolados de ação coletiva. Por outro lado, põe uma série de desafios ao pesquisador. Em nosso caso, além da grande diversidade que seria natural nesse recorte amplo, deparamo-nos, em algumas regiões, com a resistência e o receio de diversos militantes em conceder entrevistas e fornecer informações sobre suas atividades. Essa resistência foi observada, sobremaneira, na cidade de Dourados, no estado do Mato Grosso do Sul, onde os movimentos sociais têm enfrentado ameaças e situações de violência frequentes em conflitos com o agronegócio local. Alguns militantes só aceitaram ser entrevistados mediante a não-gravação do depoimento, outros se opuseram claramente a oferecer qualquer informação sobre suas atividades. Questionados sobre os motivos da recusa, foram unânimes em mencionar o contexto político hostil a suas atividades e sua existência. Nesse momento, abrir-se, ainda que para fins acadêmicos, seria colocar-se em risco. Houve também a indagação por parte de alguns sobre uma espécie de contrapartida dos pesquisadores às suas ações coletivas, seja na forma de 
doações ou de participação nas atividades das organizações entrevistadas. Isso exigiu que negociássemos e debatêssemos constantemente o sentido das nossas ações de pesquisa com os entrevistados, bem como as expectativas e contrapartidas possíveis, além de ter nos obrigado a constantemente repensar nosso planejamento de campo. De todo modo, cremos ser necessário mencionar esse contexto, na medida em que, certamente, ele é importante para entender o lugar que muitos atores coletivos ocupavam no momento de realização da pesquisa, e mostra como sua situação se alterou significativamente no curto período desde as Jornadas de Junho até o presente.

\section{Movimentos sociais na era digital}

Apesar de razoável diversidade interna, quase todos os atores coletivos aqui abordados

surgiram nas duas últimas décadas. É, portanto, a partir dos anos 2000 que começa sua história. Eles são os herdeiros imediatos dos movimentos de contestação ao neoliberalismo, surgidos no final dos anos 1990, como o movimento altermundialista, fundado em 1999, em Seattle, nos Estados Unidos, por ocasião do encontro da Organização Mundial do Comércio (OMC) e das manifestações contra as organizações multilaterais, como o FMI e o Banco Mundial, ocorridas mundo afora.

Embora haja alguma permanência da crítica ao neoliberalismo em seu bojo, esse não é mais o aspecto central e definidor dos movimentos. É possível observar algumas mudanças importantes em suas atuações, com destaque para a utilização das novas tecnologias de informação e de comunicação, responsáveis, em grande medida, pelo fortalecimento de um ativismo internacional, transnacional e pela consolidação das redes como modo de organização. Também houve a intensificação de mobilizações étnicas, religiosas, comunitárias e conservadoras, em que a cultura e a questão da identidade ganharam destaque amalgamadas a outras pautas, dando aos movimentos uma configuração multifacetada (Tarrow, 2004).

Os estudos sobre movimentos sociais passaram a apresentar novas tendências, sistematizadas por Bringel e Domingues (2015) como: i) a dicotomia entre local/global, norte/sul; ii) o decréscimo da influência da teoria marxista; iii) a ênfase dada às abordagens fenomenológicas, reflexivas e relacionais - com foco nas identidades, subjetividades coletivas, redes de pertencimento, laços de confiança (espécie de resgate da sociologia do interacionismo simbólico dos anos 1920); e iv) o rastreamento das redes sociais e cartografia dos processos sociais. 
$\mathrm{O}$ caso que inaugurou a literatura acerca dos movimentos transnacionais e do ciberativismo foram as revoltas zapatistas em 1994 no México. A partir dali, o uso da internet foi considerado uma nova forma de resistência (Alcântara, 2015; Bringel, 2015). Posteriormente, destacaram-se o PeaceNet, a Batalha de Seattle e o Fórum Social Mundial, denominados como altermundialistas. No Brasil, organizam-se, nesse período, a Marcha das Margaridas (2000); a Marcha Mundial das Mulheres (2000); o Fórum Social Mundial (2001); o Movimento Passe-Livre (2003); a Articulação dos Povos Indígenas do Brasil (2005); e o Fora do Eixo (2005), para citar alguns exemplos. Propondo organização mais horizontal, com revezamento e distribuição de tarefas em grupos, esses movimentos se caracterizam por não apresentar a liderança-referência, bem como por incorporar as tecnologias digitais em suas práticas.

Embora haja relativo consenso entre os autores do campo acerca das características definidoras desses movimentos, há um ponto de divergência que se destaca: a questão da liderança. Alguns autores entendem que a organização em rede e pela rede leva à negação de uma liderança vertical por parte dos movimentos. Para outros, o estudo das redes indica a existência de pontos mais importantes para a circulação de informações, o que pode ser interpretado como consequência de uma liderança ainda vertical. Existe também uma terceira corrente que afirma que esses movimentos dão origem a nova forma de liderança horizontal, a partir da qual todos são protagonistas das ações realizadas. Há ainda autores como Gerbaudo (2012) que problematizam uma espécie de "ideologia do horizontalismo" e defendem ser importante analisar as potencialidades e limitações dessas inovações organizacionais.

Para Bennett e Segerberg (2012), o fato de a comunicação digital ter se tornado um princípio organizador das relações sociais está associado a fenômenos macro, como a individualização e a fragmentação estrutural imanentes às sociedades pós-industriais. Os processos de individualização e fragmentação estrutural levam as pessoas a priorizar e exteriorizar seus enquadramentos pessoais, o que lhes permite trânsito maior entre os enquadramentos coletivos. Assim, torna-se cada vez menos necessário que o indivíduo se vincule formalmente a uma organização ou siga um líder para se sentir parte ou se solidarizar com uma causa, campanha ou movimento.

A partir dessas constatações, os autores propõem uma tipologia da ação coletiva na qual o primeiro tipo consiste na ação coletiva tradicional, caracterizado pela coordenação forte e centralizada da ação pelas organizações de movimentos sociais, que se utilizam da internet para gerenciar a participação e os quadros de ação coletiva. No outro extremo, o terceiro tipo é a ação conectiva, totalmente auto-organizada pela rede, com pouca ou nenhuma 
coordenação e conteúdos moldados por quadros de ação pessoais inclusivos. A partir dos anos 2010, proliferaram mais movimentos e organizações com o perfil de ação conectiva. Chama a atenção o surgimento dos coletivos e "ocupas", organizações com menor número de participantes e maior atuação orgânica. Acompanha esse processo o questionamento dos atores tradicionais da esquerda e de suas práticas, consideradas insuficientemente democráticas pelos novos atores. O segundo tipo, intermediário, configura-se como um híbrido dos dois anteriores.

Um marco para os movimentos sociais pós-2010 no Brasil foi, sem dúvida, as Jornadas de Junho, em 2013. Milhões de brasileiros (as) foram às ruas em mais de 350 municípios. Convocados, inicialmente, pelo Movimento Passe-Livre, em decorrência do aumento da passagem de ônibus, logo tiveram a aderência de outras frentes e organizações de esquerda, e passaram a ser disputados também pela narrativa midiática e por críticos ao governo petista. Nesse cenário, movimentos sociais de direita, tais como o Movimento Brasil Livre (MBL), o Revoltados Online e o Vem pra Rua despontaram no país e foram centrais para o desenrolar dos principais acontecimentos políticos subsequentes (eleições de 2014, impeachment e eleições de 2018).

Em síntese, o ciclo de protestos de 2013 foi responsável por alterar fundamentalmente o cenário do ativismo no Brasil, fazendo emergir uma série de novos atores coletivos em todo o espectro político, que, embora muito diferentes entre si, convergem na crítica à democracia brasileira.

A título de contextualização, é possível caracterizar essa crítica como remontando ao final do século XX (Manin, 2013), em um momento no qual a representação passou a ser cada vez mais mediada pelos meios de comunicação, colocando em xeque instituições de intermediação oriundas da massificação da democracia, especialmente partidos políticos e sindicatos. Ao longo desse processo, a visibilidade e centralidade da personalidade política se acentuaram. As redes digitais colaboraram para isso de modo progressivo.

Essa "metamorfose" na representação não foi capaz de dar vazão aos anseios e demandas materiais e pós-materiais (Inglehart, 2005), ao contrário, acabou por distanciar ainda mais representantes e representados. É notável como, desde as últimas décadas do século $\mathrm{XX}$, tem se difundido a compreensão de que a representação política nas democracias contemporâneas se encontra diante de grave crise, evidenciada pelas altas taxas de volatilidade eleitoral e pelo aumento do número de eleitores que desconfiam do sistema político, não se identificam com os partidos e não comparecem às urnas. 
Como observa Rousseau (2015), mundialmente, parcelas da população que se sentem desprestigiadas e materialmente abandonadas (sobretudo as classes médias) passam a ver a democracia tradicional como um modelo que não as representa e que tampouco defende seus interesses. Uma das consequências disso é a ascensão do populismo de extrema direita, fenômeno amplamente perceptível no ocidente nos últimos anos, com o crescimento da popularidade de Le Pen, na França; com as vitórias eleitorais do Brexit, no Reino Unido; do Fidezs, na Hungria; de Donald Trump, nos Estados Unidos; e de Jair Bolsonaro, no Brasil. Junto à ascensão política da direita no Brasil, houve crescimento substancial, na última década, de movimentos sociais do mesmo espectro político, que adquiriram grande influência na esfera pública nacional.

Conforme exploraremos a seguir, na esteira desse contexto político turbulento, houve diferentes tipos de respostas ao problema da representatividade, a depender do posicionamento político dos atores coletivos.

\section{Caracterização geral dos coletivos e movimentos sociais}

Ao longo da pesquisa, entrevistamos 40 atores coletivos. Poucos se autodefinem diretamente como movimentos sociais. A maioria se classifica como coletivos ou como parte de uma rede de militância mais ampla, que forma o movimento social propriamente dito (é o caso da Marcha Mundial de Mulheres de Dourados, por exemplo).

A sobreposição numérica dos coletivos sobre os movimentos, que se reflete na ênfase analítica deste trabalho, ocorre devido a, pelo menos, duas razões. Em primeiro lugar, por causa do objetivo geral do projeto temático em que esta pesquisa se inseriu: identificar novas formas de liderança política, campo no qual os coletivos se destacam. Em segundo, pelo fato de que, nas duas últimas décadas, houve grande proliferação dessas organizações, principalmente após 2010, antecipando os efeitos das Jornadas de Junho sobre a ação política. Cabe notar que os recursos necessários para fundar coletivos são relativamente pequenos, ao contrário de um movimento social, o que cria menores obstáculos para o surgimento daqueles.

Em sua maioria, as organizações que surgiram após 2010 se denominam coletivos. Estes podem ser definidos como grupos com número variável de integrantes que promovem ações coletivas focadas em determinados temas: cultura, gênero, meio ambiente, direitos humanos etc. Conforme Scherer-Warren (2006:11), os coletivos fazem parte do "associativismo local", termo cunhado para identificar as associações civis, os movimentos comunitários e os sujeitos envolvidos com causas sociais ou culturais do cotidiano. Diferente 
de outras formas de associativismo, como os movimentos sociais e as ONG, são caracterizados pela informalidade e por pouca ou nenhuma institucionalidade.

No que diz respeito à atuação dos coletivos, a autora citada os caracteriza pela luta por modos de vida alternativos, por reconhecimento ou como produtores de novas formas de expressão simbólicas. Em seu artigo subsequente (2014), há preocupação em distinguir os movimentos sociais de outros tipos de ação coletiva que ganharam destaque após as Jornadas de Junho, como as marchas e os diversos tipos de manifestação. Os coletivos estão ausentes dessa categorização mais recente. Alguns elementos da definição mais antiga de SchererWarren, todavia, permanecem atuais e foram verificados em nossa pesquisa, como a informalidade e a pouca institucionalidade que ainda caracterizam esses grupos.

A formação de redes, aspecto central de sua organização, dificulta a identificação da quantidade exata de integrantes, conferindo-lhes uma característica peculiar, que é o que chamamos de "organização em camadas". A participação é segmentada em graus diferentes, e o número de integrantes varia conforme esses níveis. O "núcleo duro" dos coletivos é, em geral, composto por poucos membros fixos e constantes. Em nível mais amplo, são integrados por outros tantos participantes ocasionais e ainda por aqueles que se definem como parte de uma rede mais ampla de coletivos que atuam em áreas semelhantes. Cada "camada" corresponde a um tipo de relação e atuação. No núcleo duro, os participantes possuem relações de afinidade mais estreitas e frequentes, compondo propriamente a identidade do coletivo. Nas camadas exteriores, as relações são mais fluidas e ocasionais, sendo mobilizadas conforme os projetos e a necessidade de atuação conjunta. De modo geral, esse arranjo garante flexibilidade e permite que os integrantes atuem em diversas frentes e coletivos simultaneamente. O coletivo Matehackers (Porto Alegre), por exemplo, possui um "núcleo duro" composto por oito integrantes. Incluídos os participantes ocasionais, reúne cerca de trinta pessoas. Já como rede, compõe uma comunidade de mais de três mil pessoas, que inclui indivíduos e diversos coletivos ligados à cultura, ao mundo digital e às universidades.

Outro fator que se destaca na caracterização dos coletivos é que, além das causas sociais que informam sua atuação, alguns, principalmente da área de cultura, organizam-se como cooperativas de trabalho, em formato que permite aos integrantes exercerem suas atividades profissionais no coletivo e delas extraírem renda, sem operar como uma empresa privada voltada ao lucro, o que será detalhado mais adiante.

No que diz respeito à área de atuação, não se diferenciam dos movimentos sociais. Porém, nos aspectos estruturais e organizativos, as diferenças aparecem com nitidez. Primeiramente, os coletivos não possuem uma base social ampla como a maioria dos 
movimentos sociais, podendo representar pequenos nichos ou subgrupos específicos dentro de uma determinada área de atuação. Configuram-se como pequenos grupos que atuam em rede com outros coletivos e movimentos, promovendo ações de menor porte e mais fluidas, podendo trabalhar por projetos ou mudar o escopo da atuação com mais facilidade que um movimento social propriamente dito.

\begin{abstract}
Os coletivos são grupos de pessoas que se organizam e não querem ter uma estrutura formal que os represente. São organizações caóticas que se formam simplesmente porque é importante estar em rede nesse momento, é importante fazer alguma coisa junto. E aí começam a surgir mais coletivos dentro da área cultural, pelo menos eu percebo tanto em São Paulo quanto aqui que a nomenclatura "coletivo" deixa de ser um termo quase ligado a uma cultura hippie de vida coletiva e passa ser algo como um agrupamento de pessoas em torno da comunicação, da cultura, enfim, que não é uma empresa, mas também não é uma pessoa. Tem alguma forma de organização ali, mas não é uma forma estruturada, que tenha um chefe, um líder, é um pouco de um e um pouco de outro, ela fica no meio termo (Coletivo Matehackers, Porto Alegre - RS).
\end{abstract}

Os movimentos sociais, como Tarrow apontou (1997), compõem um dos campos mais indefiníveis que existem. A despeito da pluralidade de definições que cerca a noção, há certa convergência em torno de determinado aspecto, que é a posse de algum arranjo institucional oriundo da convergência sobre propósitos e repertórios que lhes garanta continuidade temporal (Scherer-Warren, 2014) na disputa entre opositores e detentores do poder que caracteriza o processo político (Tilly, 1994). Essa continuidade temporal da atuação, além de lhes garantir algum grau de institucionalidade, também os difere dos coletivos, dos protestos e das manifestações ocasionais. A estabilidade se estende ao conjunto de valores e ao modo de atuação dos movimentos, menos permeáveis a mudanças do que os coletivos, posto que as transformações podem ser vistas como ameaçadoras para a própria identidade do movimento.

\title{
Formas de organização e a questão da liderança
}

A partir da nossa amostra e observando a ação coletiva no país, verificamos que a maioria dos coletivos se posiciona no espectro político da esquerda. As organizações à direita, que surgiram na esteira das Jornadas, como o Movimento Brasil Livre, o Vem Pra Rua Brasil e o Revoltados Online, embora critiquem a representação e se apresentem como "a nova política", reproduzem as formas organizativas tradicionais, com desenhos verticais: tenho um conselho que é deliberativo, estratégico, e tenho uma estrutura que tem filiais. A estrutura é parecida com uma empresa, é o pensamento cartesiano mesmo que embasa. E isso nos deu muita força, a gente acabou institucionalizando o Vem 
Pra Rua de uma maneira que, por exemplo, tivemos uma audiência pública no STF, o STF chamou o Vem Pra Rua. Então o Vem Pra Rua, apesar de não estar formalizado juridicamente, ele é uma instituição respeitada (Movimento Vem pra Rua, São Paulo - SP).

Semelhante ao Vem pra Rua no que tange à estrutura e ao modo de organização (assim como em outros aspectos), o MBL também se define como movimento político. A diferença é que possui lideranças mais claramente definidas que o primeiro, personificadas nas figuras de Kim Kataguiri e Fernando Holiday. Porém, esses não são os únicos líderes do movimento, e embora apreciada, a ideia de liderança não tem perfil determinado, nem é claramente materializada em uma única figura carismática. As lideranças podem emergir em qualquer campo, desde que sejam porta-vozes e disseminadoras autênticas dos ideais do movimento:

O político tradicional, esse, pra nós, não é o modelo exclusivo. Quando se trata do que o MBL entende como liderança, a forma não é a questão. Eventualmente, pode ser até um líder religioso, pastor de uma bancada evangélica, delegado... ainda que ele possa ter divergências com outros membros, pra nós a liderança política tem que ter a fidelidade com os valores criados pelo movimento e o compromisso com ele (MBL, São Paulo-SP).

Conforme explicou a porta-voz do Vem pra Rua, a identificação de lideranças locais em cada região do Brasil foi dos primeiros e mais fundamentais passos para a organização dos movimentos de direita em nível nacional. As lideranças locais transmitem os princípios e coordenadas dos comitês centrais dos movimentos, de modo a estabelecer alinhamento entre o local e o central.

O que eu fiz, eu montei uma liderança em cada cidade, aí quando surgiam mais lideranças daquela cidade eu colocava em contato com a liderança principal da cidade, de maneira que a gente foi montando uma árvore. Então, tem um núcleo central, que são 5 pessoas, o conselho do Vem Pra Rua, que é eleito a cada 6 meses pelos membros, por eleição indireta, o grupo nacional, com um representante de cada estado, e as lideranças municipais. Mas as decisões são tomadas nos colegiados representativos (Vem pra Rua, São Paulo - SP).

É possível, portanto, reconhecer uma estrutura híbrida nesses movimentos, com elementos de verticalização, cuja inspiração vem do universo corporativo, que coexistem com elementos mais modernos, como a formação de redes. As lideranças nesses movimentos tampouco são do tipo tradicional, representadas por uma única figura que reúne atributos carismáticos e concentra o poder em suas mãos. Diferente dos partidos de direita, que se apoiam cada vez mais em líderes carismáticos tradicionais para os representar - os híperlíderes, segundo Gerbaudo (2018), tais como Trump e Bolsonaro - as lideranças dos movimentos de direita são plurais e descentralizadas, e sua importância reside mais em sua 
capacidade de disseminar os valores do movimento, do que em tornar-se representantes oficiais dos mesmos. Essa característica, já presente nos movimentos de direita, é ainda mais acentuada nos de esquerda, sobretudo naqueles que praticam a horizontalidade. Nesse sentido, trata-se de uma "liderança suave" (soft leader), identificada pela literatura como aquela que "influencia e mobiliza emoções, cria identificações comuns e desencadeia o impulso para reuniões e protestos" (Gerbaudo, 2012:13). Em outras palavras, trata-se de uma liderança quase invisível, não personalizada e não formalizada.

Em se tratando dos movimentos sociais à esquerda, que surgem e se destacam no último decênio, observa-se algumas características semelhantes aos coletivos, situando-se como um tipo intermediário entre os movimentos tradicionais e os coletivos. De um lado, possuem causas, objetivos, princípios e práticas bem estabelecidos e uma continuidade temporal de atuação que os distingue dos coletivos (Scherer-Warren, 2014). De outro, do mesmo que estes últimos, adotam formas horizontais de organização, permitindo o revezamento de lideranças e atribuições, e as decisões são tomadas em consenso. $\mathrm{O}$ caso mais ilustrativo desse tipo de movimento é o Passe Livre, precursor das Jornadas e de nova forma de ação política no país. Reconhecido pela luta em prol da "expropriação do transporte público", o movimento se organiza de forma horizontal e a partir de grupos de trabalho. As funções são rotativas. Segundo sua carta de princípios:

Todas as pessoas envolvidas no MPL devem possuir o mesmo poder de decisão, o mesmo direito à voz e à liderança nata. Pode-se dizer que um movimento horizontal é um movimento onde todos e todas são líderes, ou onde esses líderes não existem. Desta forma, todos e todas têm os mesmos direitos e deveres, não há cargos instituídos, todos e todas devem ter o acesso a todas as informações. As responsabilidades por tarefas específicas devem ser rotatórias, para que os membros do grupo possam aprender diversas funções (MPL, São Paulo - SP).

Para Castells (2013), as novas formas de organização em rede e horizontais emanciparam os grupos sociais da lógica de comando de cima para baixo e da necessidade de líderes. Outros autores, como Klein (2002), destacam que esse tipo de organização também representou avanços em termos organizacionais, na medida em que a ausência de uma hierarquia rígida eliminou consensos forçados, deixando a estrutura dos movimentos menos burocrática e, portanto, com mais facilidade para tomar decisões:

Graças à rede, as mobilizações podem se desenvolver com uma burocracia esparsa e uma hierarquia mínima; consensos forçados e manifestos elaborados estão sendo deixados em segundo plano, substituídos por uma cultura de troca de informações constante, vagamente estruturada e, às vezes, compulsiva (Klein, 2002:4). 
Porém, a despeito de todas as expectativas e investimentos depositados nela, a horizontalidade apresentou-se como um formato que também tem seus reveses. A necessidade de consensos constantes, e a ausência de figuras de comando estabeleceram os principais limites à continuidade da atuação decisiva do MPL após as manifestações de junho de 2013, criando segundo o ex-integrante, uma dinâmica de extensas reuniões que minava a agilidade necessária às ações, além de forçar o movimento a voltar-se constantemente a si próprio e a suas questões internas, em vez de direcionar esforços aos acontecimentos que provinham da sociedade.

\begin{abstract}
O MPL sempre teve como uma de suas características centrais a crítica à "velha esquerda" (...). Os agrupamentos partidários viam as demandas por transporte de maneira instrumental, por isso as aparelhavam ou as boicotavam de acordo com as análises de seus comitês centrais. Foi para romper com essas práticas que estabelecemos como princípios a autonomia, a independência, o apartidarismo e a horizontalidade. (...) Contudo, os princípios foram transformados em nossa própria doutrina. Considerávamos essa a única perspectiva correta de atuação (...). A horizontalidade, expressa na divisão e na rotatividade de tarefas, que seria fundamental para consolidar uma democratização de saberes e não consolidar posições hierárquicas, resultou em uma ojeriza à especialização (...). A discussão democrática - fundamental para a oxigenação das mobilizações - abriu espaço para a rediscussão eterna das decisões (...). Ao procurarmos criar um movimento novo, com novas práticas, negando as práticas anteriores, nos aproximamos de um ahistoricismo, no qual não recorríamos às experiências de lutas acumuladas para pensar os atuais dilemas ${ }^{4}$.
\end{abstract}

A despeito dessa leitura produzida por um dos pioneiros, a horizontalidade ainda foi descrita como uma forma que reflete os ideais e objetivos da maior parte dos atores entrevistados, gerando gratificação quando praticada. É possível que seus limites fiquem mais evidentes em situações como a enfrentada pelo MPL: liderando uma grande manifestação em nível nacional, com a presença de atores heterogêneos e embates políticos de grande monta, compondo um cenário em que não havia tempo hábil para gastar com a produção de consenso em todas as questões. Além disso, como será discutido adiante, a horizontalidade não foi suficiente para responder à crise de representação política contemporânea do modo como alguns atores coletivos esperavam.

\title{
Formas de sustentabilidade financeira
}

A sustentabilidade financeira de uma organização tem implicações diretamente em sua autonomia, no alcance de suas ações, na sua relação com outros atores (sobretudo no que se 
refere à dependência de outras organizações e indivíduos) e na relevância que ela possui no cenário político. No amplo universo que constitui a amostra aqui representada, com coletivos compostos por duplas e por grandes grupos, com objetivos apenas político-sociais ou voltados para gerar renda aos integrantes, muito ou quase nada estruturados, a diversidade tem impacto decisivo na forma como os coletivos se sustentam. Os mais estruturados conseguem angariar as condições mínimas para disputar editais de fomento público ou privado e para realizar atividades que gerem algum tipo de renda. Outros dependem exclusivamente dos recursos dos próprios integrantes. No universo dos coletivos pequenos e pouco estruturados, a falta de recursos parece ser a dificuldade principal. Como esses coletivos não geram renda aos integrantes, estes dependem de outros trabalhos para se manter, tomando o coletivo como atividade paralela. A menor dedicação, consequentemente, torna-se obstáculo para a expansão das atividades.

É difícil você ter uma vida dentro do movimento social e você ter uma vida a parte, né, você tem que trabalhar fora, mas você tem o movimento que você gosta, então é muito difícil os dois andarem juntos. Se a gente pudesse ter a parte financeira dentro do movimento, seria muito melhor. Teria mais tempo, mais ferramentas para usar (Coletivo Flor no Asfalto, Fortaleza-CE).

Por outro lado, há coletivos que encontraram formas de organização que permitem aos integrantes a dedicação exclusiva. Um deles é o Catarse, em Porto Alegre. Fundado em 2004, com membros que decidiram formalizar o estatuto de "cooperativa de trabalho coletivo de comunicação e produção cultural" para prestar serviços de produção de conteúdos culturais e jornalismo. Assim, embora haja uma temática social que perpassa a organização e que seja formalmente definida como entidade sem fins lucrativos (requisito para concorrer a editais de fomento), ela opera como associação de profissionais que podem extrair renda dos serviços prestados, possibilitando a dedicação integral:

Se vocês querem que a força de trabalho de vocês seja o carro-chefe da vida profissional de vocês, se querem gerar trabalho e renda coletivamente, ser dono dos meios de produção, constituir um espaço que permita tudo isso, a resposta é simples, é cooperativa de trabalho. (Coletivo Catarse, Porto Alegre).

No universo dos coletivos com estruturas mais complexas, podemos citar também os exemplos do Ponte Jornalismo e do Outras Palavras, ambos com sede na cidade de São Paulo. O Outras Palavras se define como um site de análise, composto por uma rede de, aproximadamente, 700 pessoas que não são remuneradas. O que une e move esses colaboradores são os pontos de vista convergentes, "a ideia da desmercantilização do mundo, 
da reconstrução e da reinvenção da democracia", conforme explica um dos idealizadores do projeto. O site é financiado por meio de uma parceria com empreendedores da economia solidária e criativa, que anunciam nas páginas do Outras Palavras, além de receber contribuições de leitores. Os anunciantes podem contribuir com os produtos e serviços que são compartilhados com os doadores.

A Ponte, por sua vez, foi criada em 2014, por jornalistas especializados em segurança pública, com o objetivo de "defender os direitos humanos por meio de um jornalismo independente, profissional e com credibilidade". O acesso ao jornal é gratuito. Ele é custeado a partir de doações de leitores e da Open Society, entidade internacional criada por George Soros, que financia projetos em diversas áreas, incluindo a de jornalismo independente. "Mas o grande desafio da mídia independente é esse: você conseguir fazer, se sustentar financeiramente, com estrutura, com pessoal, equipamento", afirma o entrevistado. A Ponte não tem uma sede ou escritório, e a divulgação do conteúdo é feita principalmente pelo Facebook.

Enquanto os movimentos e coletivos de esquerda mencionam dificuldades para se sustentar com doações de simpatizantes, editais públicos ou por meio da venda de produtos e serviços, os movimentos de direita que entrevistamos (MBL e Vem pra Rua) afirmam não padecer do mesmo problema. O MBL possui um escritório no bairro do Itaim Bibi, em São Paulo, onde há pessoas trabalhando para criar conteúdo para as mídias sociais. O financiamento advém, principalmente, de doações de empresas e de simpatizantes. O Vem pra Rua também se financia por meio de doações, em geral, de empresários. Apenas não aceitam receber recursos de políticos e partidos, para manter o princípio do suprapartidarismo. Embora não possuam uma sede, eles mantêm uma comissão específica para captação dos recursos necessários para manter a estrutura bastante profissionalizada do movimento, que inclui assessoria de imprensa e de mídias sociais, empresas de TI, entre outros profissionais. Essa abundância de recursos é decisiva no impacto que o movimento consegue produzir de modo geral, ampliando o alcance de suas ações e de sua influência na esfera pública, sobretudo nas redes sociais, como será abordado no próximo tópico.

A gente tem sim quem cuida do Facebook, das redes, a gente tem quem cuida do fandom, a gente tem quem cuida da administração, quem cuida dos grupos, que fala com todas as cidades, que colhe depoimentos, que vê as opiniões, que quando precisa promove as pesquisas de opinião (Vem pra Rua - São Paulo - SP). 


\section{Estratégias de comunicação - o papel das mídias sociais e das novas tecnologias digitais}

É inequívoca a importância da internet e das mídias sociais para a divulgação das ações dos coletivos e movimentos contemporâneos. Na ausência de cobertura mais ampla ou de bom relacionamento com as mídias tradicionais, as novas tecnologias acabam desempenhando quase exclusivamente aquele papel. O Movimento Passe Livre, por exemplo, despreza as relações "promíscuas" existentes entre as mídias tradicionais e o empresariado, e é cauteloso na concessão de entrevistas para esses veículos, privilegiando o contato com mídias alternativas. Em sua carta de princípios, o movimento estabelece que:

O MPL deve utilizar mídias alternativas para a divulgação de ações e fomentar a criação e expansão destes meios. Já o contato com a mídia corporativa deve ser cauteloso, entendendo que estes meios estão diretamente atrelados às oligarquias do transporte e do Poder Público (MPL, São Paulo - SP).

O MBL também afirma não possuir boas relações com a mídia tradicional. Há a interpretação, por parte do movimento, de que os jornais brasileiros são tendenciosos e aliados politicamente à esquerda. Também acreditam que a imprensa possui privilégios e vínculos com o governo que a impedem de ser isenta.

O Facebook ainda é a principal ferramenta utilizada por todos os movimentos e coletivos para comunicação e divulgação das agendas e atividades. O MBL afirma ter se inspirado nos exemplos de movimentos de esquerda, como o Occupy Wall Street e o Mídia Ninja, pioneiros das "guerrilhas virtuais", para iniciar a estratégia que considera ser mais efetiva para o movimento se expandir. Embora a estrutura seja classificada como "rudimentar", operar a guerrilha virtual política, que tem o MBL como protagonista, exige bastante conhecimento técnico. Questionado sobre isso, o entrevistado lembra que alguns integrantes já possuíam conhecimento de mídias digitais antes de integrarem o movimento. Mas a inspiração para utilizar essa tática vem do exterior e de como as mídias sociais foram decisivas para formatar opiniões e decidir eleições.

O Vem pra Rua afirma possuir estrutura bastante profissionalizada, que é essencial para impulsionar as "agendas" do movimento, como foi o caso da Reforma da Previdência:

Olha, nós vamos trabalhar pra reforma da previdência, vamos precisar de boost no Facebook, a gente vai precisar contratar alguém que faça nossos posts, porque não sei se vocês repararam, mas o nosso Facebook é bastante profissional, a gente gosta. Temos uma assessora de imprensa, temos uma empresa na área de informática, que faz alguns programas, como os mapas que a gente divulga, então a gente sai procurando doações para manter essa estrutura toda. 
Mas isso não significa que a rede seja um meio isento de conflitos. Os algoritmos que governam as atividades do Facebook muitas vezes dificultam a vida dos movimentos. O MBL, por exemplo, teve diversas páginas apagadas e bloqueadas durante as eleições de 2018. Uma mudança recente dos critérios do algoritmo teve impacto muito negativo para o jornal feito pelo Ponte, fazendo a visualização de seu conteúdo cair cerca de $40 \%$ no início de 2018 . Por essa razão, o coletivo passou a estudar formas de ser menos dependente do Facebook para a divulgação de seu conteúdo. Do mesmo modo, o MBL passou a investir mais em criar seu próprio canal de notícias, nos moldes do que faz a Mídia Ninja e a TVT.

No entanto, se para muitos atores contemporâneos as mídias sociais são peça-chave de seu funcionamento e de sua própria existência, para outros, seu papel não é tão central. Primeiramente, observa-se com frequência a falta de habilidades técnicas para operar as ferramentas, bem como falta de tempo e recursos para contratar especialistas no assunto. Há, com efeito, uma disparidade muito grande entre os coletivos e movimentos no que diz respeito ao uso que fazem das redes sociais, sobretudo entre o MBL e o Vem pra Rua (estruturas muito profissionalizadas e com foco de atuação nas redes) e os demais. Assim, muitos fazem apenas postagens ocasionais de suas atividades, mas não tomam as mídias sociais como centrais em sua atuação, com exceção do WhatsApp e do Telegram, mencionados como ferramentas-chave para a comunicação interna dos coletivos, tendo papel importante em sua organização.

O nosso Facebook mal é movimentado, o nosso site sai do ar... se tem algo que funciona pro movimento é o WhatsApp, com todas as suas limitações de 3 bom dias e 4 louvores ao Senhor...É o que ainda consegue mais dinamizar a comunicação entre as ocupações, os núcleos, com uma série de críticas que podem ser feitas (MTST, Salvador - BA).

Embora algumas redes facilitem a organização da maioria dos movimentos, apenas o Vem pra Rua e o MBL disseram que se capacitaram para fazer uso delas com o objetivo claro de influenciar o debate público sobre determinados temas, como a Reforma da Previdência. Em relação aos outros movimentos entrevistados, com exceção do Ponte e do Outras Palavras, que são canais especializados de mídia alternativa, não houve relatos desse tipo de atividade entre os entrevistados.

Sabe-se que manter uma página ativa, com muitos seguidores e engajamento com o conteúdo, tornou-se uma atividade que requer diversas habilidades técnicas e recursos financeiros que a maioria dos movimentos não possuem. Com efeito, a alimentação das mídias sociais é vista por muitos como um trabalho difícil que, além de tomar o escasso 
tempo que poderiam dedicar às ações mais concretas, não gera tantos benefícios quanto se pode supor, porque o alcance delas é muito pequeno.

Porém, com isso não queremos afirmar que a disparidade na capacidade de influência nas redes sociais seja resultado direto da falta de perícia técnica. Pensar deste modo seria inverter causa e consequência. Embora esteja muito claro o papel que as redes sociais desempenham no presente como veículos de formação de opinião capazes até de definir eleições, preferimos pensá-las, em linha com outros autores como Gerbaudo (2012), que são os fatores políticos, culturais e sociais que dão forma ao ativismo e não as tecnologias em si. Como ele aponta em seu livro mais recente, as redes sociais são "famintas por dados e estão sempre em busca de expansão de tamanho e poder” (2018:5 [tradução nossa]). Os chamados "partidos digitais" estão se valendo dessa lógica para ampliar seus votos nas próximas eleições e construir uma relação mais democrática com sua base, como ele mostra no livro. Alguns atores coletivos também adotaram essa lógica para expandir sua influência, porém, nem todos foram capazes de fazê-lo. Apesar de parecer uma estratégia simples aos olhos leigos, o domínio da lógica das redes sociais demanda tempo, dinheiro e técnica. Dessa forma, embora mais democrática em vários sentidos, as redes não são um território isento de desigualdades e poder, longe disso. Além disso, outro elemento importante para entender a grande disparidade observada no poder de influência dos movimentos nas redes sociais diz respeito à própria dificuldade de comunicação e diálogo, tanto com a base quanto com um público mais amplo, que se revelou no depoimento de diversos atores coletivos de esquerda. Essa dificuldade reverbera no uso parco que alguns fazem dos recursos oferecidos pelas mídias sociais e se alinha com o problema maior da falta de representatividade.

\section{O problema da representação}

Se há algo que uniu direita e esquerda durante as manifestações de 2013 foi a crítica à falta de representatividade das velhas instituições políticas. Os principais movimentos que surgiram nessa época - com destaque para o MPL, o MBL e o Vem pra Rua - tiveram essa questão como uma de suas pautas centrais. As respostas de cada movimento foram muito diferentes: enquanto o MPL procurou criar nova forma de organização política que considerava mais democrática, o MBL e o Vem pra Rua materializaram seu rechaço às instituições políticas tradicionais emulando as organizações empresariais e compondo discurso antipetista e anticorrupção, eficazmente manipulado nas redes sociais como emblema da "nova política" pela qual lutavam. 
A crítica desses movimentos reside majoritariamente na questão da representatividade, que aparece quando a porta-voz do Vem pra Rua retrata de modo emocionado a novidade que esse e outros movimentos similares representam ao "defender o direito do brasileiro" e não de grupos específicos:

\begin{abstract}
O MBL, o Revoltados Online e o Vem pra Rua estavam nas ruas não para defender a si próprios ou algum membro daqueles grupos, mas para defender o direito do brasileiro. Pelo Brasil. E isso me encantou, e foi o que também me encantou lá nas Diretas, uma coisa nacional, para os direitos da maioria. (...) $\mathrm{E}$ inclusive, e eu adorava isso, quando alguém levantava a bandeira de um partido, a bandeira de algum interesse corporativo, ou sindicato, ou UNE, todo mundo falava "abaixa a bandeira que aqui não tem isso não". Aqui é pelo Brasil, só vale bandeira brasileira. (...) Então acho que é essa a diferença, porque começou a surgir um movimento nacional de política não partidária. E é aí que nós nos encaixamos, como políticos não partidários (Vem pra Rua, São Paulo - SP).
\end{abstract}

Questionada sobre o que significa lutar pelo Brasil, a porta-voz faz associação com os valores dos próprios movimentos de direita, ressaltando a incapacidade das instituições políticas de desempenhar o papel que, supostamente, tais movimentos exerceriam no presente:

\begin{abstract}
O brasileiro é liberal na economia e conservador nos costumes, isso é o brasileiro. Eu acho que o brasileiro tem um range aí entre liberal e conservador muito claro. Só que nós não temos isso espelhado no nosso Congresso. Os nossos representantes não falam sobre isso, não se preocupam com isso. Por isso que a gente olha pro Congresso e fala "eles não me representam", porque tem uma minoria que entrou lá e que trabalha pra isso, mas a grande maioria trabalha por qualquer outra coisa menos isso. O Congresso ainda não nos representa, a gente precisa aprender a votar, aprender a ler as pessoas que estejam nesse range, que é a população brasileira. (Vem pra Rua, São Paulo - SP).
\end{abstract}

No caso dos movimentos e coletivos de esquerda, a horizontalidade continua sendo o formato presente em suas tentativas de criar formas mais democráticas de organização. Porém, o que se nota (tanto a partir da pesquisa quanto da autocrítica feita pelos atores coletivos) é que, embora torne os movimentos internamente mais democráticos, não foi ainda um recurso suficiente para criar relação mais democrática dos movimentos com a sociedade, por meio do diálogo e da comunicação efetiva.

O exemplo mais contundente foi o da Marcha Mundial de Mulheres que atua em Dourados, no Mato Grosso do Sul. Embora façam parte de uma rede internacional de militantes, as integrantes entrevistadas se queixaram da falta de interesse e suporte da rede mais ampla para os problemas locais, que incluem a miséria e problemas graves de violência doméstica. Além disso, há a própria dificuldade do movimento, composto majoritariamente por mulheres universitárias, de estabelecer diálogo com as mulheres da periferia e das aldeias indígenas. A começar pelo próprio idioma (muitas indígenas não falam português), somado à 
falta de acesso à internet, há obstáculos significativos para estabelecer comunicação e conexão. No contexto em que militam, as redes pouco podem fazer para auxiliá-las.

O uso das mídias sociais é visto majoritariamente como um recurso que facilita a comunicação e o engajamento dos atores coletivos, fortalecendo modos mais participativos de ação e representação políticas. Porém, o que se observou, na maioria dos casos, é que isso falha em ocorrer, sobretudo em contextos periféricos.

\begin{abstract}
E essa tecla eu bato sempre, a gente tem que sair da academia, a esquerda brasileira se encastelou nas universidades e não saiu mais de lá, e essa é a grande dificuldade dos movimentos sociais porque eles acabam repetindo isso. (...) Eu vou chegar no interior do Maranhão, que é uns dos estados com pior IDH e vou dizer: "Oi, tudo bem? Vim falar sobre homo-trans-fobia. O que é isso? O que é homo-trans-fobia?". Eu tô falando pra quem? (Coletivo Curta Diversidade - São Luís - MA).
\end{abstract}

É bastante conhecida a definição de Bennet e Segerberg (2015) da "ação conectiva", em que há cada vez menos necessidade de uma vinculação do indivíduo a uma organização ou liderança para fazer parte de um movimento. No entanto, não parece ser isto o que se observa nos depoimentos aqui presentes. Ao contrário, ao mencionarem seus problemas de comunicação, os atores deixam entrever a dificuldade de cimentar laços de identificação entre eles e o grupo que pretendem representar, bem como a falta que esses laços fazem. Como lembra Gerbaudo (2020), há nas mídias sociais um potencial muito grande para facilitar esse processo de identificação coletiva, porém, é possível acrescentar que esse processo só pode ocorrer onde haja pontos em comum passíveis de ser interligados. Onde existe uma dificuldade prévia de conexão, a rede torna-se de pouca valia.

\title{
Considerações finais
}

A maioria dos coletivos e movimentos entrevistados compartilham de algumas características fundamentais que devem ser compreendidas no contexto da história da ação coletiva no Brasil e no bojo de suas transformações recentes em nível mundial.

Os coletivos proliferaram de modo notório no Brasil na última década, seguindo a tendência mundial dos protestos no contexto que se convencionou diagnosticar como "crise das democracias contemporâneas". Surgem para contestar e se contrapor às organizações políticas tradicionais, sobretudo aos partidos políticos, materializando sua crítica em formas de organização horizontais, em que as lideranças são rotativas ou inexistentes. Porém, nota-se um custo evidente para levar a cabo esse formato. A horizontalidade exige que os movimentos se voltem com frequência para suas questões internas, o que cobra um preço no que diz 
respeito à agilidade da atuação ao compasso das demandas exteriores. Além disso, a horizontalidade direciona o problema da falta de representação das instituições políticas tradicionais para ser resolvido no interior dos movimentos, como se, ao modificar as suas estruturas, pudessem mudar todo o entorno das relações com a sociedade, o que não se materializou na prática.

Quanto ao uso das novas tecnologias da informação, embora a maior parte desses atores já tenha nascido dentro do universo das redes, seu papel é bastante heterogêneo, o que não costuma aparecer na literatura, que tende a tratar da importância das mídias sociais de modo uniforme. De fato, uma das características mais importantes dos movimentos contemporâneos é a organização em redes que se formam e se desfazem conforme os projetos e as pautas do momento, dando mais fluidez às ações. Porém, embora tenham sido decisivas para organizar manifestações e ações de maior porte com grande rapidez, há uma grande disparidade entre os atores coletivos em sua capacidade de utilização das redes como ferramenta de comunicação e como modo de fortalecer a representação. Enquanto alguns dispõem de maiores recursos para utilizá-las a seu favor, outros as percebem como ferramentas de menor importância para sua atuação.

Por fim, a crise de representatividade das democracias contemporâneas é um dos pontos mais complexos dessa discussão e que, junto à articulação em rede, vem a ser o eixo que conecta todas as organizações aqui tratadas, a despeito de seu posicionamento ideológico. Embora essa crise constitua uma das causas da emergência notável de atores coletivos a partir do início da década, é inegável que também os afeta de maneira negativa. Houve o anseio de criar novas formas de atuação política, e a horizontalidade representou um dos aspectos fundamentais dessa idealização. Contudo, em um universo em que tais movimentos trabalham com grande escassez de recursos, o direcionamento dos esforços para criar novas dinâmicas internas acaba não somente os distanciando das formas tradicionais e consolidadas da militância histórica, como também comprometendo um aspecto central da atuação de todo movimento social, que é, em última instância, a capacidade de representar algum anseio social.

De certo modo, a população não pôde ser incluída no projeto de formas mais democráticas de atuação política e isso parece ter sido decisivo para os rumos que a própria sociedade tomou após as Jornadas de Junho: na direção oposta dos anseios iniciais dos movimentos. O "ninguém me representa" também acabou os atingindo em grande medida. Tanto é assim que: houve espaço significativo para o crescimento dos movimentos de direita, 
a partir do vácuo de representação sentido pela população brasileira. Como disse a porta-voz do Vem pra Rua: "nós representamos o Brasil, aqui só vale a bandeira brasileira!".

\section{Referências}

ALCÂNTARA, Lívia Moreira (2015), "Ciberativismo e movimentos sociais: mapeando discussões". Aurora: Revista de Arte, Mídia e Política, v. 8, n. 23, pp. $73-97$ [Consult. 13-04-2020]. Disponível em: https://revistas.pucsp.br/index.php/aurora/article/view/22474

BENNETT, Lance; SEGERBERG, Alexandra (2012), "The logic of connective action: Digital media and the personalization of contentious politics". Information, communication e society, v. 15, n. 5 , pp. 739-768 [Consult. 08-05-2020].

Disponível em: https://www.tandfonline.com/doi/abs/10.1080/1369118X.2012.670661

BRINGEL, Breno (2015), "Social movements and contemporary modernity: internationalism and patterns of global contestation", in Breno Bringel e José Maurício Domingues (eds.), Global Modernity and Social Contestation. Londres/California/New Delhi, SAGE, pp. 122-138.

CASTELLS, Manuel (2013), Redes de indignação e esperança: movimentos sociais na era da internet. Trad. Carlos Alberto Medeiros. Rio de Janeiro, Editora Zahar.

GERBAUDO, Paolo (2012), Tweets and the Streets: Social Media and Contemporary Activism. London, Pluto Press. Press.

(2018), The Digital Party: Political Organisation and Online Democracy. London, Pluto

GOHN, Maria da Glória (2014), Manifestações de junho de 2013 no Brasil e praças dos indignados no mundo. Petrópolis, RJ, Vozes. . (2017), Manifestações e protestos no Brasil. São Paulo, Cortez.

INGLEHART, Ronald (2005), Modernization, Cultural Change, and Democracy. USA, Editora Cambridge.

KLEIN, Naomi (2002), "Farewell to 'end of history': organization and vision in anti-corporate movements”, Socialist Register 2002: A World of Contradictions. London, Merlin, pp. 1-14.

MAIR, Peter (2013), Ruling the void: the hollowing of Western democracy. London,

Verso books.

MANIN, Bernard (2013), A democracia do público reconsiderada. Novos estud. - CEBRAP, São Paulo, n. 97, pp. 115-127, 2013.

MELUCCI, Alberto (2003), Challenging codes: collective action in the information age. London, Press Syndicate of the University of Cambridge.

ROUSSEAU, Dominique (2015), Radicaliser la démocratie: Propositions pour une refondation. Éditions du Seuil, avril 2015, edition format Kindle.

TARROW, Sidney (1997), El Poder em Movimiento: movimentos sociales, la acción colectiva e la política. Madrid, Alianza Editorial. 
TARROW, Sidney; MCADAM, Douglas; TILLY, Charles (2004), Dynamics of Contention. New York and London, Cambridge University Press.

TILLY, Charles (1994), "Social movements as historically specific clusters of political performances". Berkeley Journal of Sociology, Berkeley, n. 38, pp. 1-30 [Consult. 05-04-2020]. Disponível em: https://www.jstor.org/stable/41035464?seq=1

SCHERER-WARREN, Ilse (2006), "Das mobilizações às redes de movimentos sociais". Sociedade e Estado, Brasília, v. 21, pp. 109-130 [Consult. 12-01-2020]. Disponível em: https://www.scielo.br/scielo.php?pid=S0102-69922006000100007\&script=sci_abstract\&tlng=pt

. (2014), "Dos movimentos sociais às manifestações de rua: o ativismo brasileiro no século XXI". Política \& Sociedade (Impresso), v. 13, n. 28, pp. 13-34 [Consult. 06-01-2020]. Disponível em: https://periodicos.ufsc.br/index.php/politica/article/view/2175-7984.2014v13n28p13 


\begin{abstract}
This paper presents partial results of empirical research realized in different regions of Brazil, conducted to collective actors, from interviews analysis realized in the states of São Paulo, Bahia, Maranhão, Rio Grande do Sul, Ceará e Mato Grosso do Sul. The questions were about the structure of the organization, the conception of political and collective action, the role of leaders, and the form of the organization's communication. Aiming to observe diverse contemporary ways of political and cultural activism in the country, we highlight the personages that emerged from the recent political struggle, focus on the critique to the representation, paying particular attention to the collectives.
\end{abstract}

Keywords: Social movements; collectives; political activism; cultural activism; horizontalidade; political representation.

\title{
Resumen
}

El artículo presenta los resultados parciales de una investigación empírica realizada con actores colectivos de diferentes regiones de Brasil, a partir del análisis de entrevistas realizadas en los estados de São Paulo, Bahía, Maranhão, Rio Grande do Sul, Ceará y Mato Grosso do Sul. Se plantean cuestiones sobre la estructura, la organización, la concepción de la acción política y colectiva, el rol de los líderes y las formas de comunicación de las organizaciones. Para observar los diversos modos contemporáneos de activismo político y cultural en el país, destacamos los temas que surgieron en la reciente disputa política con un enfoque en la crítica a la representación, señalando un tipo que aún ha sido poco estudiado por la literatura: los colectivos.

Palabras clave: movimientos sociales; colectivo; activismo político; activismo cultural; horizontalidad; representación política. 